\title{
Sensor Ultrasonik HCSR04 Berbasis Arduino Due untuk Sistem Monitoring Ketinggian
}

\author{
Fitri Puspasari, Imam Fahrurrozi, Trias Prima Satya, Galih Setyawan, \\ Muhammad Rifqi Al Fauzan, dan Estu Muhammad Dwi Admoko \\ Departemen Teknik Elektro dan Informatika Sekolah Vokasi, Universitas Gadjah Mada \\ Jl. Yacaranda, Caturtunggal, Kec. Depok, Kabupaten Sleman, Daerah Istimewa Yogyakarta 55281
}

\begin{abstract}
Intisari
Saat ini perkembangan dunia digitalisasi semakin berkembang. Pada pengukuran panjang umumnya hanya bisa diukur melalui pengukuran manual yaitu mengukur perangkat yang ingin diketahui panjangnya. Namun, sekarang dunia digitalisasi mampu melakukan pengukuran tanpa menyentuh perangkat yang akan diukur. Salah satunya adalah dengan memanfaatkan sumber gelombang suara atau biasa disebut sebagai gelombang ultrasonik. Tujuan dari penelitian ini adalah untuk membuat prototype alat ukur jarak digital berbasis mikrokontroler Arduino Due menggunakan sensor HCSR04. Metode penelitian yang digunakan adalah metode uji perbandingan langsung dan pengukuran secara telemetri. Hasil pengukuran ditampilkan dalam perangkat komputer untuk memudahkan pembacaan. Perancangan ini dikendalikan melalui Arduino Due. Hasil pengujian prototype alat dapat berjalan dengan baik dan bisa diakses secara real time.
\end{abstract}

\begin{abstract}
At present the development of the digitalization world is growing. Length measurements generally can only be measured through manual measurement that measures the device that wants to know its length. However, now the world of digitalization is able to make measurements without touching the device to be measured. One of them is by utilizing sound wave sources or commonly referred to as ultrasonic waves. The purpose of this study was to prototype Arduino Due microcontroller digital distance measuring devices using HCSR04 sensor. The research method used is a direct comparison test method and telemetry measurement. Measurement results are displayed in a computer device to facilitate reading. This design is controlled through Arduino Due. The prototype testing results of the tool can run well and can be accessed in real time.
\end{abstract}

Keywords: sensor; ultrasonik; HCSR04; Arduino due.

*Corresponding author: fitri.puspasari@ugm.ac.id

http://dx.doi.org/10.12962/j24604682.v15i2.4393

2460-4682 @DDepartemen Fisika, FSains-ITS

\section{PENDAHULUAN}

Panjang merupakan besaran pokok yang dapat diukur menggunakan alat ukur seperti mistar, mikrometer sekrup dan jangka sorong. Pembacaan pada alat ukur panjang biasanya dalam bentuk skala. Skala-skala tersebut dibandingkan dengan panjang standar yang ada. Dalam dunia metrologi, salah satu faktor yang menyebabkan sumber terjadinya kesalahan adalah kesalahan paralaks yang terjadi saat penggunaan alat ukur manual. Kesalahan paralaks sendiri merupakan bentuk kesalahan pembacaan hasil ukur yang disebabkan oleh keterbatasan fungsi penglihatan. Sehingga, kesalahan seperti ini dapat menimbulkan beberapa dampak pada hasil pengukuran, salah satunya adalah nilai terukur menjadi tidak sah kebenarannya. Hal tersebut dikarenakan akan berdampak langsung pada kualitas hasil produksi yang dihasilkan oleh proses produksi massal.

Saat ini perkembangan dunia digitalisasi semakin berkembang. Pada pengukuran panjang umumnya hanya bisa diukur melalui pengukuran manual yaitu mengukur perangkat yang ingin diketahui panjangnya. Namun, sekarang dunia digitalisasi mampu melakukan pengukuran tanpa menyentuh perangkat yang akan diukur. Salah satunya adalah dengan memanfaatkan sumber gelombang suara atau biasa disebut sebagai gelombang ultrasonik. Sensor ultrasonik mampu mengkonversi gelombang bunyi kedalam beberapa satuan seperti jarak, ketinggian dan kecepatan. Teknik pengukuran jarak/panjang ini menggunakan gelombang ultrasonik di udara termasuk metode echo pulsa, pancaran pulsa dikirim ke media transmisi dan dipantulkan oleh sebuah objek pada jarak tertentu. Waktu yang diambil dari pemancar ke penerima sebanding dengan jarak objek [1]. Sensor HCSR04 adalah sensor pengukur jarak berbasis gelombang ultrasonik. Keunggulan sensor ini adalah jangkauan deteksi sekitar $2 \mathrm{~cm}$ sampai kisaran 400-500 cm dengan resolusi $1 \mathrm{~cm}$. Sensor HCSR04 adalah versi low cost dari sensor ultrasonic PING buatan parallax. Perbedaaannya terletak pada pin yang digunakan. HCSR04 menggunakan 4 pin sedangkan PING buatan 


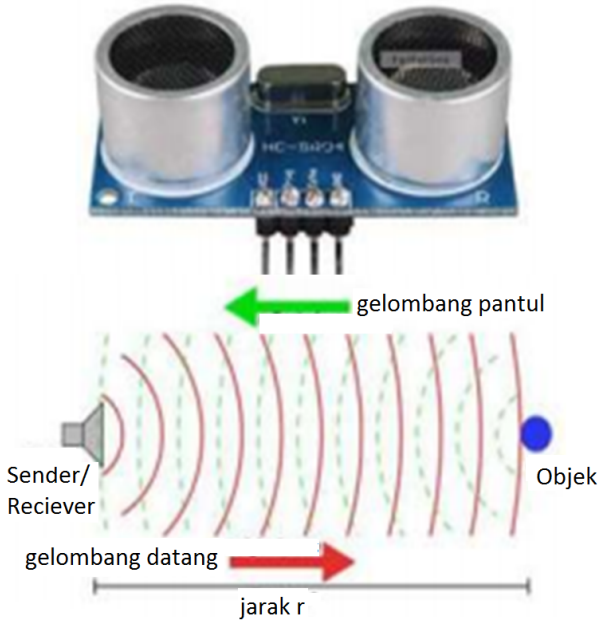

Gambar 1: Sensor jarak ultrasonik dan prinsip kerjanya [2].

Parallax menggunakan 3 pin.

Tujuan dari penelitian ini adalah untuk membuat prototipe alat ukur jarak digital berbasis mikrokontroler Arduino Due menggunakan sensor HCSR04, melakukan uji pengukuran manual serta melakukan uji monitoring pengukuran data secara telemetri dengan sensor ultrasonik. Dalam sistem pengukuran jarak ini sensor ultrasonik HCSR04 dihubungkan dengan arduino Due. Pemrograman dan bagian perangkat keras sensor ultrasonik berinteraksi dengan arduino.

\section{Ultrasonic ranging module HCSR04}

Sensor ultrasonik tipe HCSR04 merupakan perangkat yang digunakan untuk mengukur jarak dari suatu objek. Kisaran jarak yang dapat diukur sekitar 2-450 cm. Perangkat ini menggunakan dua pin digital untuk mengkomunikasikan jarak yang terbaca. Prinsip kerja sensor ultrasonik ini bekerja dengan mengirimkan pulsa ultrasonik sekitar $40 \mathrm{KHz}$, kemudian dapat memantulkan pulsa echo kembali, dan menghitung waktu yang diambil dalam mikrodetik sebagaimana digambarkan dalam Gambar 1. Kita dapat memicu pulsa secepat 20 kali per detik dan itu bisa tentukan objek hingga 3 meter [2].

\section{Arduino Due}

Arduino Due adalah sebuah board mikrokontroler yang didasarkan pada ATmega 328 sebagaimana ditunjukkan pada Gambar 2. Arduino merupakan platform elektronik populer yang dibuat pada mikrokontroler (arsitektur AVR Atmel dan arsitektur ARM), dan komponen pelengkap yang memfasilitasi pemrograman dan berinteraksi dengan sirkuit lain. Karakteristik teknis dari papan mikrokontroler Arduino Due dirangkum dalam Tabel I.

Arduino Due adalah papan mikrokontroler berdasarkan ATEL SAM3X8E ARM Cortex-M3 CPU. Ia memiliki 54 pin input / output digital, 12 input analog, 4 UART, $84 \mathrm{MHz}$ clock, koneksi USB OTG yang mampu, 2 DAC, 2 TWI, colokan listrik, header SPI, header JTAG, tombol reset dan tombol hapus. Arduino Due software terdiri dari compiler bahasa pemograman standard dan sebuah boot loader yang dieksekusi
TABEL I: Karakteristik mikrokontroler Arduino Due [3].

\begin{tabular}{ll}
\hline \hline Specification & Value \\
\hline & \\
Microcontroller & AT91SAM3X8E \\
Operating Voltage & $3 \mathrm{~V}$ \\
Input Voltage (recommended) & $7-12 \mathrm{~V}$ \\
Input Voltage (limits) & $6-20 \mathrm{~V}$ \\
Digital I/O pins & 54 \\
Analog Inputs Pins & 12 \\
Analog Outputs Pins & 2 (DAC) \\
Total DC Output Curent & $130 \mathrm{~mA}$ \\
on all I/O lines & \\
DC Current for 3.3 V Pin & $800 \mathrm{~mA}$ \\
DC Current for 5 V Pin & $800 \mathrm{~mA}$ \\
Flash Memory & $512 \mathrm{~KB}$ all avaiable \\
& for the user applications \\
SRAM memory & $96 \mathrm{~KB}$ (two banks: \\
& $64 \mathrm{~KB}$ and 32KB) \\
Clock Speed & $84 \mathrm{MHz}$ Back to top \\
\hline
\end{tabular}

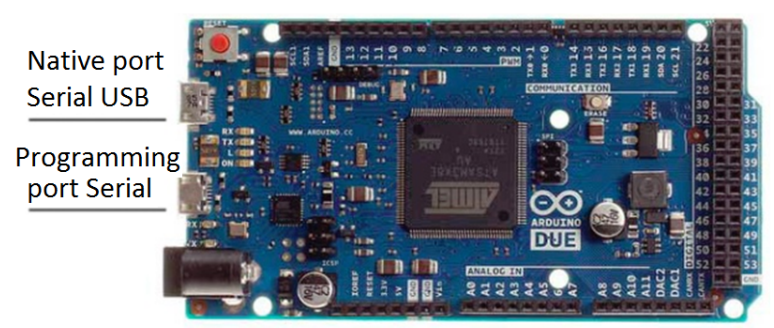

Gambar 2: Arduino Due microcontroller board [3].

dalam microkontroller. Software Arduino yang digunakan adalah driver dan IDE. IDE (Integrated Development Environment) suatu program khusus untuk suatu komputer agar dapat membuat suatu rancangan atau sketsa program untuk papan Arduino [4].

\section{METODOLOGI}

Daftar peralatan yang digunakan pada penelitian ini adalah: mikrokontroler Arduino Due, modul ESP8266, sensor ultrasonik, komputer, shield v2.0, dan kabel jumper. Metode penelitian yang digunakan pada pembuatan alat ini yaitu analisis kebutuhan, studi pustaka, perancangan alat, dan pengujian alat. Perancangan sistem monitoring untuk mengukur jarak dari jarak jauh secara real-time. Sensor yang digunakan yaitu HCSR04 dengan unit pengendali Arduino Due. Pada perangkat lunak Arduino Due terdapat 2 program yang akan disusun, yaitu program untuk pengujian sensor ultrasonik untuk perbandingan langsung (manual) dan untuk monitoring ketinggian muka air yang ada di tandon air sebuah kandang ternak ayam. Gambar 3 menunjukkan coding program untuk uji alat secara manual berbasis arduino.

Pada Gambar 4 ditunjukkan bahwa sistem menggunakan mikrokontroller Arduino Due sebagai pengolah data input dari 


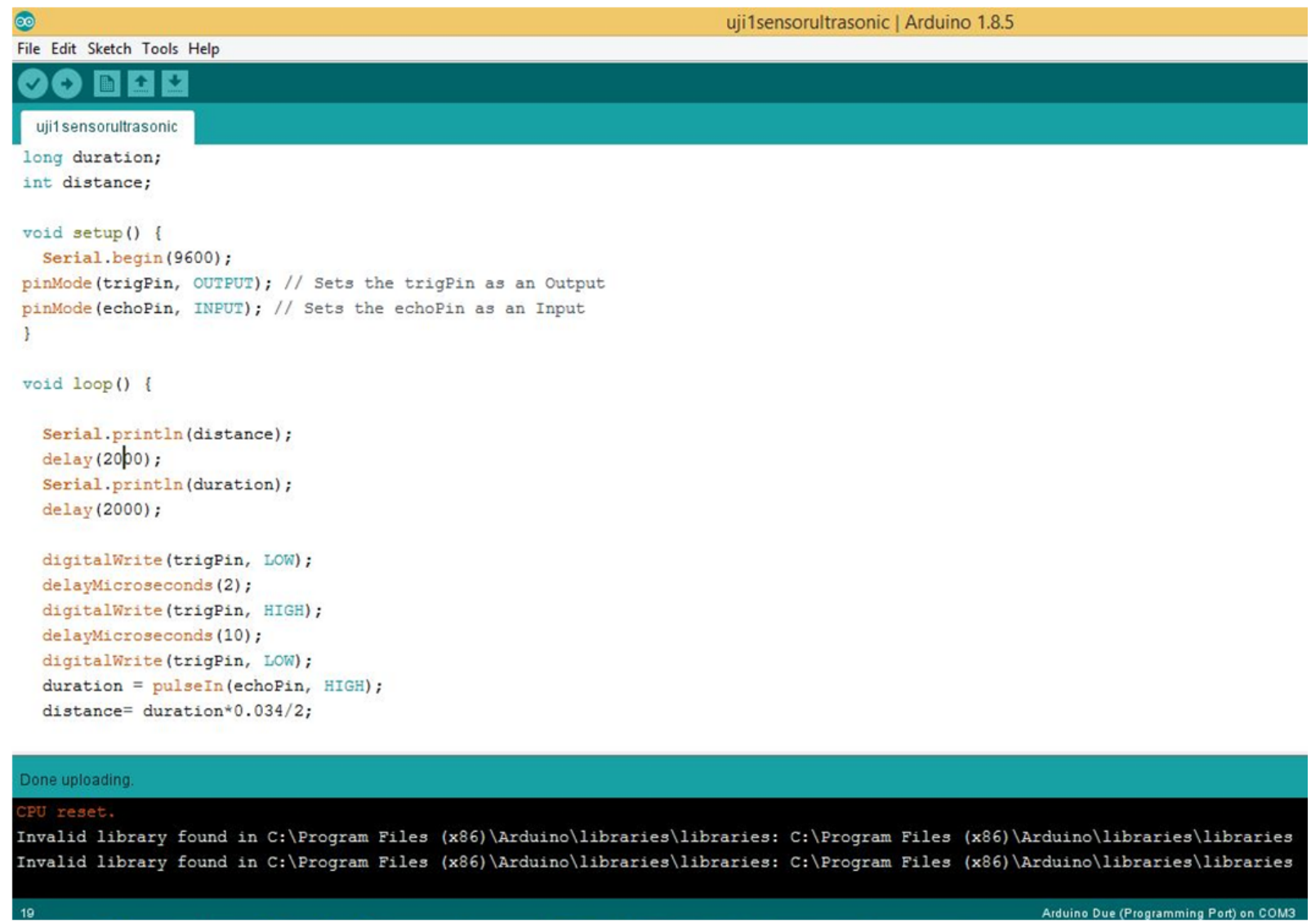

Gambar 3: Program pada lembar kerja Arduino.

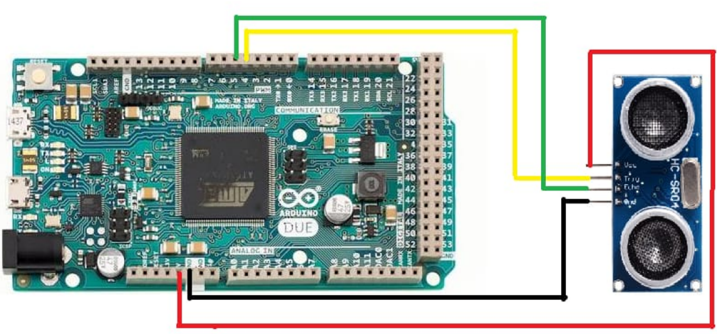

Gambar 4: Arduino Due terhubung dengan sensor HCSR04.

sensor sehingga dapat menghasilkan output yang dinginkan. Pada sistem ini tersambung dengan sensor ultrasonic tipe HCSR04. Sensor HCSR04 digunakan untuk mengukur jarak/ketinggian. Pada bagian perancangan perangkat keras membuat rangkaian mulai dari rangkaian sensor ultrasonik ditunjukkan pada gambar keseluruhan sistem (Gambar 5).

Pada sistem perangkat keras ini juga terdapat ESP8266 sebagai transceiver untuk melakukan koneksi pada jaringan wifi. Hasil bacaan sensor yang telah diolah Arduino Due dikirimkan ke plat form IoT things board menggunakan ESP8266 [5].

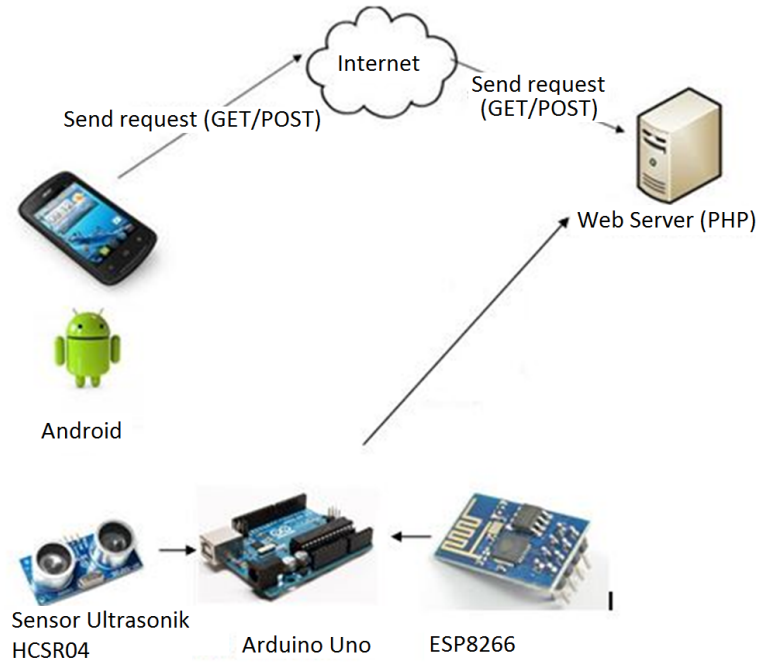

Gambar 5: Skema penelitian secara keseluruhan.

\section{HASIL DAN PEMBAHASAN}

Pembuatan dan uji coba prototipe dilakukan di laboratorium. Pada uji coba sistem telemetri (secara realtime) diaplikasikan untuk mengukur ketinggian level air pada 


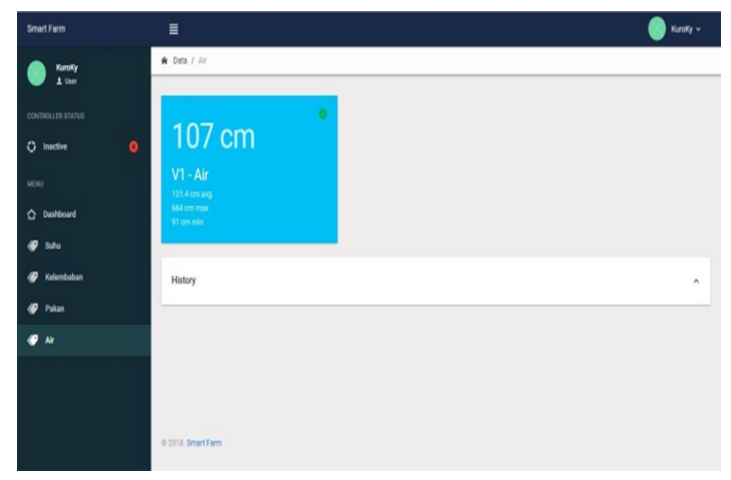

(a)
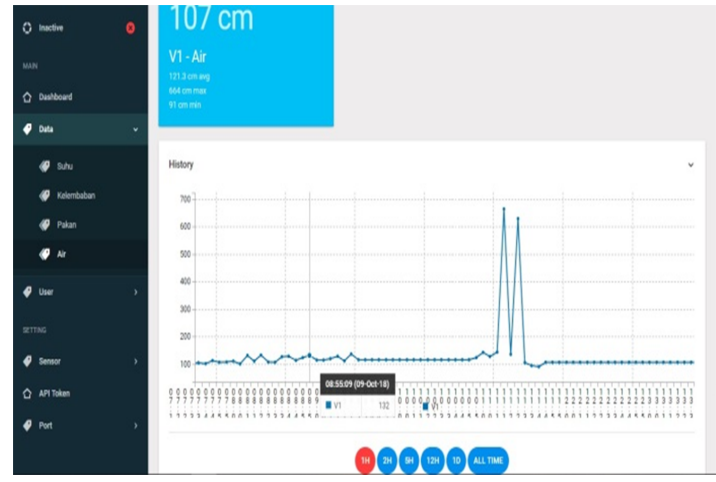

(b)

Gambar 6: Tampilan data pengukuran sensor HCSR04 via Website (a)realtime (b) histori data.

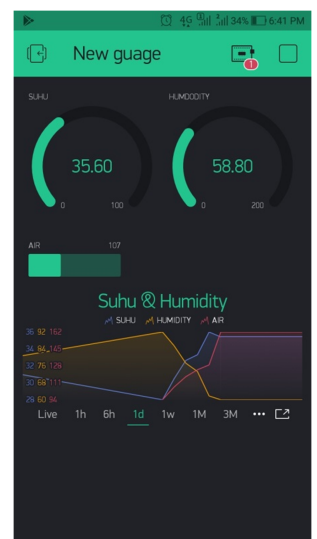

Gambar 7: Tampilan data sensor pada aplikasi Blynk.

tandon air disebuah kandang ternak ayam broiler. Pembuatan dan pengujian prototipe alat dilakukan pada perangkat keras dengan pengambilan data menggunakan ESP8266 yang di desain untuk komunikasi berbasis wifi. Modul ESP8266 ini memiliki output serial TTL dan GPIO. ESP8266 juga memiliki kemampuan untuk networking yang lengkap dan menyatu baik sebagai client maupun sebagai Access Point. Data tersebut dapat di akses melalui aplikasi Blynk pada smartphone dan melalui website secara realtime sebagaimana ditunjukkan pada Gambar 6 dan Gambar 7.

Blynk merupakan sebuah layanan server yang digunakan untuk mendukung project Internet of Things. Aplikasi ini sangat membantu dalam sistem telemetri, antara lain pengontrolan jarak jauh, menampilkan data dari masingmasing sensor yang terhubung, menyimpan data, memberi tanda/notifikasi [6]. Aplikasi Blynk digunakan dalam penelitian ini dengan tujuan untuk control dan monitoring hardware secara jarak jauh menggunakan komunikasi data internet ataupun intranet (jaringan LAN). Kemampuan untuk menyimpan data dan menampilkan data secara visual baik menggunakan angka, warna ataupun grafis semakin memudahkan dalam pembuatan project dibidang Internet of Things. Sifat dari Blynk adalah sebagai dashboard digital dengan fasilitas antar muka grafis dalam pembuatan projectnya.

\section{SIMPULAN}

Studi pendahuluan pengukuran ketinggian menggunakan sensor ultrasonik HCSR04 berbasis Arduino Due dapat digunakan untuk mengukur ketinggian air secara realtime melalui website ataupun aplikasi Blynk.
[1] C.H. NeerajaSoni, C.H.Sarita, S. Maheshwari, B. Sahu, B. Jain, G. Shrivastava, "Distance Measurement using Ultrasonic Sensor and Arduino", International Journal of Engineering Science and Computing, vol. 7, no. 3, pp. 5991-5992, 2017.

[2] A. Soni, A. Aman, "Distance Measurement of an Object by using Ultrasonic Sensors with Arduino and GSM Module", International Journal of Science Technology \& Engineering, vol.4, no. 11, pp.23-28, 2018.

[3] http://www.farnell.com/datasheets/1682211.pdf
[4] L. Bitjoka, M. Ndje, A.T. Boum, J. Song-Manguelle, "Implementation of quadratic dynamic matrix control on arduino due ARM cortex-M3 microcontroller board", Journal of Engineering Technology, vol. 6, no. 2, pp. 682-695,2017.

[5] S. Sunitha, "Distance Measurement using Ultrasonic Sensor and Node MCU", International Research Journal of Engineering and Technology, vol.4, no. 6, pp.1794-1797, 2017.

[6] https://docs.Blynk.cc/ 